\title{
Study of knowledge, perception, and practice of patients regarding fasting requirements for blood glucose testing
}

\author{
Hazra A. ${ }^{1 *}$, Mandal S. ${ }^{2}$, L. Jawalekar S. ${ }^{3}$, Rawtani J. ${ }^{4}$, Marlecha M. ${ }^{5}$ \\ DOI: https://doi.org/10.17511/ijmrr.2021.i01.01 \\ 1* Asmita Hazra, Assistant Professor, Department of Biochemistry, Government Medical College, Pali, Rajasthan, India. \\ 2 Saptarshi Mandal, Associate Professor, Department of Transfusion Medicine and Blood Bank, All India Institute of Medical Sciences \\ (AIIMS), Jodhpur, Rajasthan, India. \\ 3 Seema L. Jawalekar, Professor and Head, Department of Biochemistry, Government Medical College, Pali, Rajasthan, India. \\ 4 Jairam Rawtani, Senior Professor and Head, Department of Biochemistry, Dr. Sampurnanand Medical College, Jodhpur, Rajasthan, India. \\ 5 Minal Marlecha, MBBS Student, Government Medical College, Pali, Rajasthan, India.
}

Background: Patient preparation is one of the least standardized parts of the preanalytic phase of testing. Fasting blood glucose requires fasting for 8-12 hours as per various guidelines and also has several other requirements. Lack of communication, understanding, or compliance regarding hoursof-fasting, water-intake, avoidance of caloric snack/beverage, the sudden change in smoking, exercise, alcohol, medication, etc. introduces preanalytic errors. Method: To evaluate awareness, understanding, and compliance with fasting requirements, a face-to-face survey was done on outpatients in a Government Hospital in Pali, Rajasthan, India. Relatively more educated internet users were surveyed as controls through an online SurveyMonkey tool. Results: 98 patients and 187 controls participated in the study. Perception about fasting requirements ranged from 0-17 hours. $71 \%$ of patients and $35 \%$ of controls perceived that nobody explained to them the duration or nature of fasting. The different sources of information had been used in different proportions by patients and controls. For imparting understanding and compliance about duration, and other requirements of fasting, the instruction was usually incomplete but still much more effective ( $p$ value $=0.000002$ ) than formal education level $(p$-value $=0.024)$. Conclusion: $71 \%$ of patients and $35 \%$ of controls did not receive instructions for fasting. $40 \%$ of those instructed showed better compliance, but awareness was incomplete. The instruction was more effective than formal education in improving awareness and compliance. Improved awareness was strongly associated with receiving instruction and weakly associated with formal education but financial status showed only a weak negative association.

Keywords: Fasting for Diagnostic Laboratory Tests, Patient Preparation, Under-fasting and Overfasting

\section{Corresponding Author}

Asmita Hazra, Assistant Professor, Department of Biochemistry, Government Medical College, Pali, Rajasthan, India.

Email: hazra.asmita@gmail.com

\section{How to Cite this Article}

Hazra A, Mandal S, Jawalekar SL, Rawtani J, Marlecha M. Study of knowledge, perception, and practice of patients regarding fasting requirements for blood glucose testing. Int J Med Res Rev. 2021;9(1):01-12. Available From https://ijmrr. medresearch.in/index.php/ijmrr/article/view/1240

\begin{tabular}{|c|c|}
\hline $\begin{array}{c}\text { Manuscript Received } \\
2020-11-28\end{array}$ & $\begin{array}{c}\text { Review Round } 1 \\
2020-12-08\end{array}$ \\
\hline $\begin{array}{c}\text { Conflict of Interest } \\
\text { No }\end{array}$ & $\begin{array}{c}\text { Funding } \\
\mathrm{Nil}\end{array}$ \\
\hline
\end{tabular}

Manuscript Received No
Review Round 3

Riew Round 2

Ethical Approval Yes $5 \%$

\section{To Browse}

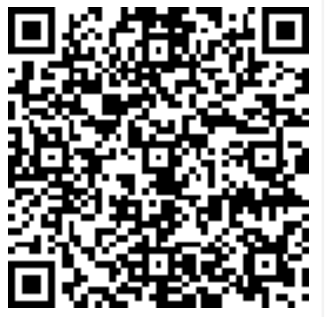

Accepted 2020-12-25

Plagiarism X-checker

(c) 2021 by Asmita Hazra, Saptarshi Mandal, Seema L. Jawalekar, Jairam Rawtani, Minal Marlecha and Published by Siddharth Health Research and Social Welfare Society. This is an Open Access article licensed under a Creative Commons Attribution 4.0 International License https://creativecommons.org/licenses/by/4.0/ unported [CC BY 4.0]. 


\section{Introduction}

The preanalytic phase, i.e. the series of steps before the actual testing of a laboratory investigation, is known to incur significantly more errors $(50-70 \%)$ than the analytic (5-15\%) and the post-analytic phases (10-30\%) [1]. The regulated environment of the laboratory and the implementation of rigorous quality controls have more than decimated the analytic errors. However, the pre-analytic and postanalytic phases are much less regulated, especially at the extreme ends of the process loop (the brainto-brain loop) $[1,2]$. A particularly problematic area of the preanalytic phase involves those requiring patient preparation [3].

Fasting is the most well-known type of patient preparation for diagnostic medical testing. Though a multitude of laboratory parameters are significantly affected by fasting state, e.g. glucose, triglyceride, insulin, alkaline phosphatase, bilirubin, iron, CReactive Protein, alanine aminotransferase, albumin, calcium, sodium, magnesium, potassium, uric acid, some of the routine hematology count parameters, etc. [4-7] it is glucose for which fasting measurement is most common patient preparation asked by a medical laboratory. Under-fasting and over-fasting, both are detrimental to glucose measurements, for diagnostic as well as monitoring purposes [8].

Fasting requirements are not comprehensively defined in most of the guidelines themselves [9] and are not adequately communicated or explained to patients $[10,11]$. "Fasting" in laboratory science is not merely a term that is intuitive from its face value and is different from other forms of medical fasting eg "Nil Per Oral (NPO)" before surgery or endoscopic procedures etc. Depending on the test, fasting requires specifying the duration and a list of allowed/desired and prohibited types of activities before and during the fast [4].

For example, the fasting duration for fasting blood glucose may vary from 8-12 hours (usually overnight) depending on country and guideline [4,12]. It also requires 24 hours of alcohol restriction. Any caloric intake in the form of solid or liquid is prohibited during the total duration of fasting. Smoking, exercise, chewing gums, and taking nonessential medication in the morning before sampling is discouraged [13]. However, hydration in the form of clear water is allowed or rather encouraged, and thus it is very different from NPO.
When fasting blood glucose is a part of an OGTT, it needs to be even more stringent [14]. WHO recommends OGTT to be administered in the morning after three days of caloric unrestricted diet (daily $>150 \mathrm{~g}$ of carbohydrate) along with usual physical activity, and a moderate (30-50g) carbohydrate-containing meal in the evening before the test day. In addition to all the usual specifications of fasting, WHO recommends documenting additional factors for OGTT e.g. medications, inactivity, infection, etc. which could affect the interpretation of the test.

Counseling patients and clarifying their doubts in their language is necessary to improve perception and compliance regarding the above factors. However, this step is often missed or remains inadequate, due to a multitude of logistic issues. Delivery of the information is controllable and is a relatively standardizable part of the process. However, what is not exactly controllable is the level of understanding, subjective perceptions, and compliance of the patient, which might potentially be affected by the education or socioeconomic status of the patient.

The primary aim of this study was to evaluate the awareness perception and compliance about the duration and nature of fasting required for fasting blood glucose testing among patients accessing the hospital laboratory. The current study intended to identify the types of gaps in the communication, and instructions that are more frequently missed, which could help predict corrective interventions.

The current study also planned to assess the impact of education, income, and other factors on understanding and adherence to the instruction. To this end, a control group was recruited from educated ( $>10$ th pass) adult internet users from the same locality, who were competent to respond to a similar online questionnaire but were not themselves medical professionals.

\section{Materials and Methods}

The study was conducted after permission from the Institutional Ethics Committee and the study adhered to the Principles of Geneva Council for International Organizations of Medical Sciences. A pre-tested face to face anonymous questionnairebased survey was conducted on ambulatory patients waiting for phlebotomy in the out-patient section of Government Bangur Hospital, Government Medical College Pali, Rajasthan. 
Patients were selected using a convenient sampling method. After obtaining informed consent from the patient, the survey was administered nonjudgmentally in the native language of the patients (Hindi or Marwari).

A comparable Online SurveyMonkey tool (SurveyMonkey, San Mateo, CA, USA) [15] was used to survey adult internet users from the same locality, who completed school education or more. This questionnaire was in English.

Mentally incapable, deaf, or dumb patients were excluded from the face-to-face survey. Fully trained Health professionals e.g. doctors, technicians, nurses, etc. were also excluded from both forms of survey.

The questionnaire included questions on

- Basic demographic data including age, gender, locality

- Formal education level

- Financial status (family annual income)

- Perception of hours of fasting required

- Perception about whether to restrict

- Water intake

- Beverage

- Light breakfast

- Religious eatables e.g. Prasad for Hindu worship or Sehri (pre-dawn meal) for Ramadan etc.

- Smoking

- Drinking alcohol

- Medication

- Exercise during the fasting

- Change of, in the previous three days, exercise habit, food

- Instruction/explanations about fasting received

- Whether instructed at all

- Who instructed

- Verbal or in writing

- What was the number of hours they fasted in practice

- Did they take any edibles in the morning

- What food or beverage they ate before starting the fasting
For financial status, an annual income classification 1-5 was adapted in a way similar to a modified Kuppuswami scale 2019 update [16] (Table 2) to cover the range of annual income of affluent patients and controls.

The education levels were numerically categorized 0-4 (Table 1) based on a schema adapted from ISCED (International Standard Classification of Education) and modified according to the prevailing nomenclature of our country. The patients were chosen randomly, thus had varied education levels. But the control group, by definition, completed school education, i.e. passed a "School-Leaving" board examination or Matriculation or equivalent. Data processing and statistical analysis were done with Microsoft Excel, IBM SPSS 23.0, and R 4.0.3. with Rcmdr.

\section{Results}

For the survey, 310 subjects, including 110 patients and 200 controls, were approached and were informed about the details of the questionnaire. The response was received from 285 subjects (92\% response) including 98 patients ( $89 \%$ response) and 187 controls (93\% response) who consented to participate in the survey. Control: The patient ratio was 1.9:1 among respondents. The patients included $54(55 \%)$ females and $44(45 \%)$ males and controls included 103 (55\%) females and 83 $(45 \%)$ males. Male to Female ratio 1.25 in both groups. The age range was $18-82$ years (Mean \pm $\mathrm{SD}=42.9 \pm 17.8 \mathrm{y}$ ) in the patient group and $18-52$ years $(21.1 \pm 6.5 y)$ in the control group. Education information was not provided by 2 patients (2\%), and financial information was not provided by 7 patients $(7 \%)$ and 12 controls $(6 \%)$.

Table-1: Educational stratification of patients and controls.

\begin{tabular}{|c|c|c|c|c|}
\hline \multirow{2}{*}{\multicolumn{2}{|c|}{ Education: Categories }} & \multicolumn{2}{|c|}{ Group } & \multirow{2}{*}{$\begin{array}{l}\text { Total } \\
(\%)\end{array}$} \\
\hline & & $\begin{array}{l}\text { Control } \\
(\%)\end{array}$ & $\begin{array}{l}\text { Patient } \\
(\%)\end{array}$ & \\
\hline Uneducated & 0 & & $\begin{array}{l}40 \\
(42 \%)\end{array}$ & $\begin{array}{l}40 \\
(14 \%)\end{array}$ \\
\hline Primary School (Class I-V) & 1 & & $\begin{array}{l}14 \\
(15 \%)\end{array}$ & $14(5 \%)$ \\
\hline Secondary School (Class VI-X) & 2 & & $\begin{array}{l}21 \\
(22 \%)\end{array}$ & $23(8 \%)$ \\
\hline Matriculated (Passed Secondary Board) & 3 & $56(30 \%)$ & $\begin{array}{l}10 \\
(10 \%)\end{array}$ & $\begin{array}{l}64 \\
(23 \%)\end{array}$ \\
\hline $\begin{array}{l}\text { Graduate or Pursuing Bachelor or higher } \\
\text { education }\end{array}$ & 4 & $\mid \begin{array}{l}131 \\
(70 \%)\end{array}$ & $\mid \begin{array}{l}11 \\
(12 \%)\end{array}$ & $\mid \begin{array}{l}142 \\
(50 \%)\end{array}$ \\
\hline
\end{tabular}


Total 187 96 283

Education levels are stratified into 5 categories and the number of patients and controls in each. By design, the control group consisted of people who have passed high school and thus did not have any population in the first three education categories.

Table-2: Financial stratification of Patients and Controls.

\begin{tabular}{|l|l|l|l|l|}
\hline \multirow{2}{*}{ Annual Income: Financial Category } & \multicolumn{2}{|c|}{ Group } & \multirow{2}{*}{ Total } \\
\cline { 3 - 5 } & & Control (\%) & Patient (\%) & \\
\hline$<2.5$ Lakh & 1 & $35(20 \%)$ & $8(9 \%)$ & $43(16 \%)$ \\
\hline $2.5-5$ Lakh & 2 & $40(23 \%$ & $16(18 \%)$ & $56(21 \%)$ \\
\hline $5-7$ Lakh & 3 & $39(22 \%)$ & $10(11 \%)$ & $49(18 \%)$ \\
\hline 7-10 Lakh & 4 & $26(15 \%)$ & $28(31 \%)$ & $54(20 \%)$ \\
\hline$>10$ Lakh & 5 & $35(20 \%)$ & $29(32 \%)$ & $64(24 \%)$ \\
\hline Total & & 175 & 91 & 266 \\
\hline Financial status was assessed as per the annual family income and \\
stratified into 5 categories. Annual income was noted in Indian National \\
Rupees (INR) Lakhs per year. 1 Lakh = 100,000. Note that patients are \\
significantly more affluent than the controls: N=266, Pearson Chi- \\
Square=20.563, df=4, p-value=0.00038.
\end{tabular}

Perception and practice of fasting duration varied from 0 hours to 17 hours in both groups. A staggering $71 \%(70 / 98)$ of the patients and $35 \%$ $(65 / 187)$ of educated respondents perceived that nobody instructed or explained to them anything about the nature of the fasting.

Table-3: Number (\%) of patients, controls, and total, that were instructed or aware of fasting.

\begin{tabular}{|l|l|l|l|}
\hline \multicolumn{1}{|c|}{ Group } & Patient & Control & Total \\
\hline N & 98 & 187 & 285 \\
\hline Instructed & 30 & 122 & 135 \\
& $(31 \%)$ & $(65 \%)$ & $(47 \%)$ \\
\hline Aware that some fasting is needed for some & 43 & 148 & 191 \\
tests & $(44 \%)$ & $(79 \%)$ & $(67 \%)$ \\
\hline No knowledge about fasting duration or & 53 & 80( & 133 \\
conditions for blood glucose test & $(54 \%)$ & $43 \%)$ & $(47 \%)$ \\
\hline Fasting duration known for blood glucose test & 15 & 65 & 80 \\
Fasting conditions (other than duration) for & 23 & 86 & 109 \\
blood glucose test known & $(23 \%)$ & $(46 \%)$ & $(38 \%)$ \\
\hline Fasting duration and conditions for glucose test & $0(0 \%)$ & 36 & 36 \\
all known & $(15 \%)$ & $(35 \%)$ & $(28 \%)$ \\
\hline
\end{tabular}

Among patients, $11 \%$ of the uninstructed knew the fasting duration right, whereas $40 \%$ of instructed patients knew the fasting duration right. The instruction did make a significant improvement in awareness about the duration ( $N=98$, Pearson Chi Square $=5.321, d f=1, p$-value $=0.021)$.
Of the instructed patients, 46\% knew the fasting conditions (other than duration) right and of those not instructed only $14 \%$ knew them, i.e. instruction again had a very significant impact $(\mathrm{N}=98$, Pearson Chi-Square $=11.504, \mathrm{df}=1, \mathrm{p}$-value $=0.001)$.

Since both the outcomes, right duration, and right conditions, were improved by the instructions, the overall knowledge was improved even more significantly. In the total population $\mathrm{N}=285$, Pearson Chi-Square $=29.463, \quad d f=3, \quad p$ value $=1.79 * 10-6$.

Among controls, $26 \%$ of uninstructed and 39\% of instructed knew the fasting duration right. The impact of instruction was not significant (Chi-square $\mathrm{p}$-value $=0.071)$. On the other hand, $51 \%$ of instructed controls and $37 \%$ of uninstructed controls knew the fasting conditions (other than time) right. Impact of instruction again was not significant (Chisquare $p$-value $=0.69)$. However, among controls impact of instruction on knowing fasting duration and conditions all right was significantly associated with instructions $(\mathrm{N}=187, \quad$ Pearson ChiSquare $=8.435, \mathrm{df}=1, \mathrm{p}$-value $=0.004)$.

Perception of fasting duration on the average was lower than the proper target $(8-12 \mathrm{~h})$ in both patients and controls (i.e. under-fasting), but

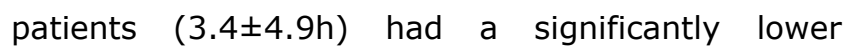
duration in their perception than controls $(5.4 \pm 3.7 \mathrm{~h})$ and the difference was highly significant (Student's t-test $\mathrm{p}$-value $=0.0004$ ). Among controls, $79 \%$ and patients $44 \%$ were aware that some fasting is necessary for some tests in general.

Table-4: Source of Information in Patients and Controls.

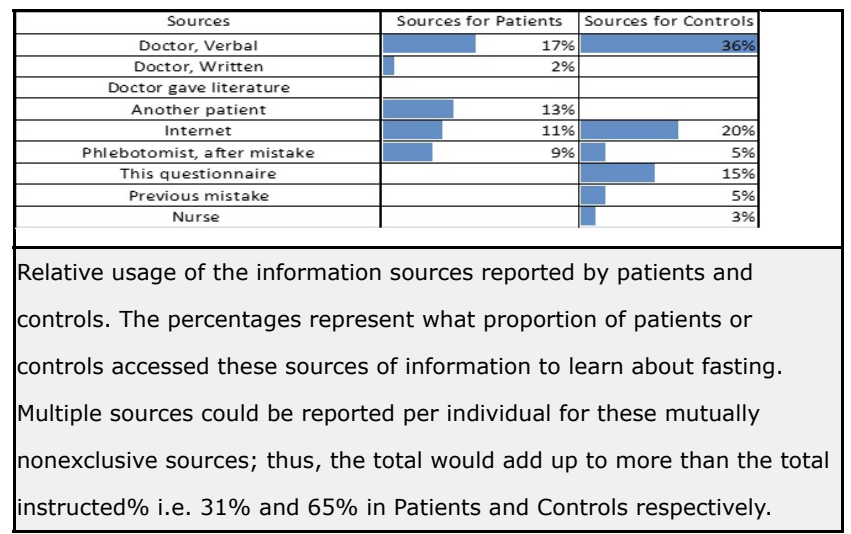

The commonest sources of information for patients were doctors ( $17 \%$ verbal instructions, $2 \%$ written instruction, Printed reading material not received by any). 
Other common sources included another patient $(13 \%)$, the internet $(11 \%)$, explanation by phlebotomists after improper fasting (9\%), counseling after this questionnaire $(6 \%)$, and nurses $(2 \%)$. Top sources for the control were doctors $(36 \%)$, Internet $(20 \%)$, this questionnaire $(15 \%)$, nurses $(5 \%)$, and previous improper fast $(4 \%)$.

In the patient group, of those instructed $83 \%$ were aware and $72 \%$ were compliant in practice about avoiding light snacks during fast. Whereas, among uninstructed patients, $48 \%$ claimed to be aware and only $15 \%$ were compliant about light snacks. Awareness and compliance about avoidance of tea/coffee was $67 \%$ and $44 \%$ for instructed vs $30 \%$ and $0 \%$ for the uninstructed respectively.

An alarming $33 \%$ of the instructed patients continued to perceive that religious food could be taken in the morning, and $11 \%$ even consumed religious food. As much as $55 \%$ of the uninstructed patients perceived religious food was allowable and $19 \%$ consumed them. Interestingly $100 \%$ of both instructed and uninstructed claimed to be aware of alcohol and smoking. Their compliance was close to $95 \%$.

Even among the controls, $30 \%$ thought tea/coffee is allowed, $10 \%$ thought snacks are allowed and 3\% thought religious food was allowed. Only $35 \%$ of controls could guess the correct fasting duration for glucose despite their higher formal educational status.

Among patients, the commonest sources (nonexclusive) of information were: doctors (17\% verbal, $2 \%$ written, $0 \%$ print), another patient $(13 \%)$, internet $(11 \%)$, phlebotomist $(9 \%)$, counselling after this questionnaire (6\%). Top information sources for controls were: doctors $(36 \%)$, Internet $(20 \%)$, this questionnaire $(15 \%)$, nurses $(5 \%)$, and previous improperly prepared tests (3\%). Among the instructed controls $83 \%$ understood and $72 \%$ were compliant about light snacks. Among un-instructed controls, $48 \%$ claimed to be aware and $15 \%$ adhered to the requirement to avoid snacks.

Awareness and compliance about tea/coffee among patients was $67 \%$ and $44 \%$ for instructed vs $30 \%$ and $0 \%$ for the uninstructed. As much as $33 \%$ of instructed patients thought religious food could be taken in the morning during fasting, and $11 \%$ took them.
On the other hand, $55 \%$ of the uninstructed patients thought it was allowable and $19 \%$ took them. $100 \%$ of both instructed and uninstructed patients claimed to be aware of alcohol and smoking restrictions and compliance was close to $95 \%$. Among the controls $27 \%$ thought tea/coffee is allowed, 10\% thought snacks are allowed and 3\% thought religious food was allowed. Thus, controls also had misconceptions, but to a much smaller extent than patients.

Table-5: Perception of what is allowed during fasting among patients and controls.

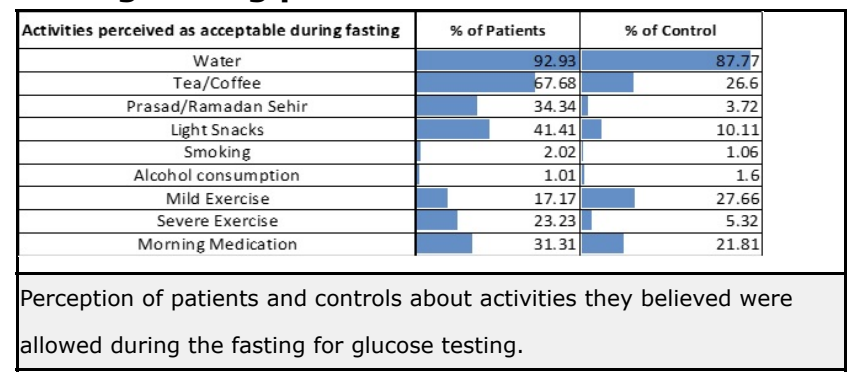

Among patients, awareness and compliance about tea coffee were $67 \%$ and $44 \%$ respectively for the instructed vs $30 \%$ and $0 \%$ for the uninstructed. Even $33 \%$ of instructed thought religious food could be taken, and $11 \%$ took them. In contrast $55 \%$ of the uninstructed thought they were allowable and $19 \%$ consumed them. Interestingly $100 \%$ of both instructed and uninstructed claimed to be aware of alcohol and smoking and compliance was close to 95\%.

Among controls $30 \%$ thought tea/coffee is allowed, $10 \%$ thought snacks are allowed and 3\% thought religious food was allowed. Only $20 \%$ of controls could guess the correct range for fasting duration for glucose.

Fig-1: Density histograms of Perception of Fasting duration in patients versus controls.

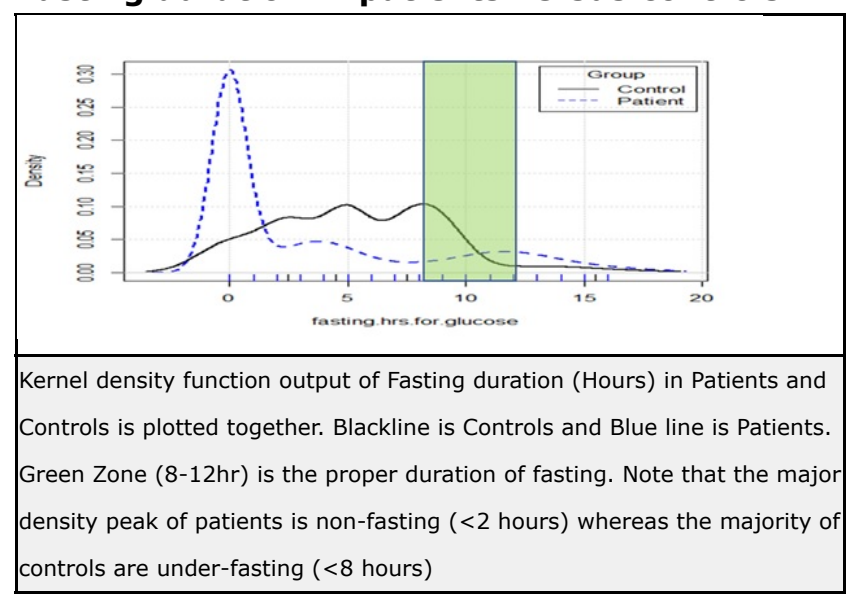


Only $15(15 \%)$ patients and 65 (35\%) controls recalled fasting for the proper duration. Though the control group was also grossly improper, mostly under-fasting, they had statistically better performance than patients in terms of hours of fasting required. When plotted as a continuous variable, perception of hours of fasting duration needed for glucose was lower than the target (8$12 \mathrm{~h}$ ) in both patients and controls (i.e. majority reported under-fasting), but patients $(3.4 \pm 4.9 \mathrm{~h})$ had a significantly lower duration than controls $(5.4 \pm 3.7 \mathrm{~h})$ and the difference was highly significant (Student's t-test $p$-value $=0.0004$ )

Table-6: Fasting Duration Categories in Patients versus Controls.

\begin{tabular}{|c|c|c|c|c|c|c|}
\hline & \multirow{2}{*}{\begin{tabular}{|l|}
\multicolumn{1}{|c|}{ Fasting } \\
duration proper \\
Fast $8-12 \mathrm{hr}$ \\
\end{tabular}} & \multicolumn{3}{|c|}{ Fasting duration improper } & \multirow[t]{2}{*}{ Total } \\
\hline & & & $\begin{array}{l}\text { No Fast } \\
(<2 \mathrm{hr})\end{array}$ & $\begin{array}{l}\text { Under fast } \\
(2-8 \mathrm{hr})\end{array}$ & $\begin{array}{l}\text { Overcast } \\
(>12 h)\end{array}$ & \\
\hline \multirow[t]{2}{*}{ Group } & Control & 65 & 28 & 82 & 12 & 187 \\
\hline & Patient & 15 & 59 & 17 & 7 & 98 \\
\hline \multicolumn{2}{|l|}{ Total } & 80 & 87 & 99 & 19 & 285 \\
\hline
\end{tabular}

Table 6: Patients and controls stratified by fasting duration: proper fasting duration (8-12 hours), not fasting ( $<2$ hours), under-fasting (2-8 hours), and over-fasting ( $>12$ hours). The difference between the two groups in the distribution of the discontinuous duration categories was also significant: $\mathrm{N}=285$, Chi-Square $=64.816, \mathrm{df}=3, \mathrm{p}$-value $=5.491 * 10-14$.

In the combined population of patients and controls, educational categories were cross-tabulated against fasting duration categories.

Table-7: Fasting duration versus education categories.

\begin{tabular}{|c|c|c|c|c|c|c|}
\hline & & \multicolumn{4}{|c|}{ Fasting Duration } & \multirow[t]{2}{*}{ | Total } \\
\hline & & $\begin{array}{l}\text { Fast 8- } \\
12 \mathrm{hr}\end{array}$ & $\begin{array}{l}\text { No Fast } \\
(<2 \mathrm{hr})\end{array}$ & $\begin{array}{l}\text { Overfast } \\
(>12 h)\end{array}$ & $\begin{array}{l}\text { Underfast } \\
(<8 \mathrm{hr})\end{array}$ & \\
\hline \multirow{5}{*}{$\begin{array}{l}\text { Education } \\
\text { Category }\end{array}$} & .0 & 4 & 28 & 3 & 5 & 40 \\
\hline & 1.0 & & 9 & 2 & 1 & 14 \\
\hline & 2.0 & & 8 & 1 & 7 & 23 \\
\hline & 3.0 & & 16 & 3 & 23 & 64 \\
\hline & 4.0 & & 25 & 10 & 62 & 142 \\
\hline Total & & 80 & 86 & 19 & 98 & 283 \\
\hline \multicolumn{7}{|c|}{$\begin{array}{l}\text { Fasting duration categories were cross tabulated against education } \\
\text { categories. } \mathrm{N}=283, \mathrm{df}=12, \text { Pearson } \text { Chi-Square }=55.545, \mathrm{p}- \\
\text { value }=1.45 * 10-7 \text {. }\end{array}$} \\
\hline
\end{tabular}

Table-8: Proper Fasting duration crosstabulated against Education categories.

\begin{tabular}{|l|l|l|l|l|}
\hline \multicolumn{2}{|c|}{} & \multicolumn{2}{|c|}{ Fasting Duration Proper } & \multirow{2}{*}{ Total } \\
\cline { 2 - 5 } \multicolumn{2}{c|}{} & .0 & 1.0 & \\
\hline Education Category & .0 & 36 & 4 & 40 \\
\cline { 2 - 5 } & 1.0 & 12 & 2 & 14 \\
\hline
\end{tabular}

\begin{tabular}{|l|l|l|l|l|}
\hline 2.0 & 16 & 7 & 23 \\
\hline 3.0 & 42 & 22 & 64 \\
\hline 4.0 & 97 & 45 & 142 \\
\hline Total & 203 & 80 & 283 \\
\hline
\end{tabular}

Fasting for 8-12 hours was considered proper fasting duration and the rest were clubbed into improper fasting duration. Education categories were cross-tabulated against proper fasting duration. $\mathrm{N}=283$, Pearson ChiSquare $=9.983, \mathrm{df}=4, \mathrm{p}$-value $=0.041$.

Chi-Square analysis (Table 7 and 8 ) showed that knowledge of proper fasting duration had a significant association with a better education. However, clubbing the different types of misconceptions about durations into a single improper duration category leads to a partial loss of significance, mainly because the relatively more educated people tended to cluster within one subtype (under-fasting) of the improper duration of fasting, and less educated people had higher tendency to be in another subtype (non-fasting).

Overall knowledge was classified into 4 ordinal categories: scored as 3 if conditions and duration both all known, 2 if conditions were known but duration not known, and 1 if only duration known and 0 if neither is known.

Table-9: Instruction and overall knowledge about fasting for a glucose test.

\begin{tabular}{|c|c|c|c|c|c|c|}
\hline & & \multicolumn{4}{|c|}{ Overall Knowledge of fasting } & \multirow[t]{2}{*}{ Total } \\
\hline & & 0 & 1 & 2 & 3 & \\
\hline \multirow[t]{2}{*}{ Instructed } & .0 & 83 & 18 & 28 & 6 & 135 \\
\hline & 1.0 & 49 & 26 & 45 & 30 & 150 \\
\hline \multicolumn{2}{|l|}{ Total } & 132 & 44 & 73 & 36 & 285 \\
\hline \multicolumn{7}{|c|}{$\begin{array}{l}\text { The overall knowledge is cross-tabulated against instructed status. Overal } \\
\text { knowledge was categorized as } 3 \text { if all correct, } 2 \text { if fasting conditions } \\
\text { correct, } 1 \text { if duration only correct and } 0 \text { if all wrong. } \mathrm{N}=285 \text {, Pearson Chi- } \\
\text { Square }=29.463, \mathrm{df}=3, \mathrm{p} \text {-value }=1.79 * 10-6 \text {. }\end{array}$} \\
\hline
\end{tabular}

Table-10: Education and overall knowledge about fasting for the glucose test.

\begin{tabular}{|c|c|c|c|c|c|c|}
\hline & & \multicolumn{4}{|c|}{ Overall Knowledge of fasting } & \multirow[t]{2}{*}{ Total } \\
\hline & & 0 & 1 & 2 & 3 & \\
\hline \multirow[t]{5}{*}{ Education Category } & .0 & 29 & 3 & 7 & 1 & 40 \\
\hline & 1.0 & 10 & 2 & 2 & 0 & 14 \\
\hline & 2.0 & 11 & 3 & 5 & 4 & 23 \\
\hline & 3.0 & 22 & 14 & 20 & 8 & 64 \\
\hline & 4.0 & 59 & 22 & 38 & 23 & 142 \\
\hline \multicolumn{2}{|l|}{ Total } & 131 & 44 & 72 & 36 & 283 \\
\hline $\begin{array}{l}\text { Education Categories } \\
\text { Knowledge categoriz } \\
\text { if duration only corre } \\
23.491, d f=12, p \text {-va }\end{array}$ & $\begin{array}{l}\text { ross- } \\
\text { as } 3 \\
\text { and } \\
=0 .\end{array}$ & $\begin{array}{l}0 \text { if } \\
24 .\end{array}$ & $\begin{array}{l}\text { yains } \\
t, 2\end{array}$ & $\begin{array}{l}\text { erall } \\
\text { ting }\end{array}$ & $\begin{array}{l}\text { vledge } \\
\text { ditions }\end{array}$ & $\begin{array}{l}\text { verall } \\
\text { rect, } 1 \\
\text { are }\end{array}$ \\
\hline
\end{tabular}


Educational categories had a significant association with better overall knowledge which however was not as significant as the impact of instruction. There was a positive Spearman Correlation of +0.185 between education categories and overall knowledge, which was very significant ( $p$ value $=0.002$ )

In contrast to instruction and educational categories, financial categories did not have any significant association with fasting duration ( $N=266$, Pearson Chi-Square $=11.990, \quad \mathrm{df}=12, \quad \mathrm{p}$ value $=0.446$ ), but there was a mildly significant association with knowing other conditions right $(\mathrm{N}=266$, Pearson Chi-Square $=10.796, \mathrm{df}=4$, $\mathrm{p}-$ value $=0.029)$. On a closer look, the association showed a weak negative Spearman correlation $(R=$
-0.112 ) however the correlation was not statistically significant $(p$-value $=0.068)$.

Table-11: Financial category and overall knowledge about fasting for a glucose test.

\begin{tabular}{|c|c|c|c|c|c|c|}
\hline & & \multicolumn{4}{|c|}{ Overall Knowledge of fasting } & \multirow[t]{2}{*}{ Total } \\
\hline & & 0 & 1 & 2 & 3 & \\
\hline \multirow[t]{5}{*}{ Financial Category } & 1.0 & 17 & 4 & 13 & 9 & 43 \\
\hline & 2.0 & 27 & 9 & 11 & 9 & 56 \\
\hline & 3.0 & 16 & 10 & 19 & 4 & 49 \\
\hline & 4.0 & 31 & 11 & 8 & 4 & 54 \\
\hline & 5.0 & 33 & 8 & 17 & 6 & 64 \\
\hline Total & & 124 & 42 & 68 & 32 & 266 \\
\hline \multicolumn{7}{|c|}{$\begin{array}{l}\text { Financial categories cross-tabulated against overall knowledge. Overall } \\
\text { Knowledge categorized as } 3 \text { if all correct, } 2 \text { if fasting conditions correct, } 1 \\
\text { if duration only correct and } 0 \text { if all wrong. } \mathrm{N}=266 \text {, Pearson Chi-Square } \\
19.675, \mathrm{df}=12, \mathrm{p} \text {-value }=0.073 \text {. }\end{array}$} \\
\hline
\end{tabular}

2A: Spearman Correlation +0.130 , p-value $=0.029^{*}$

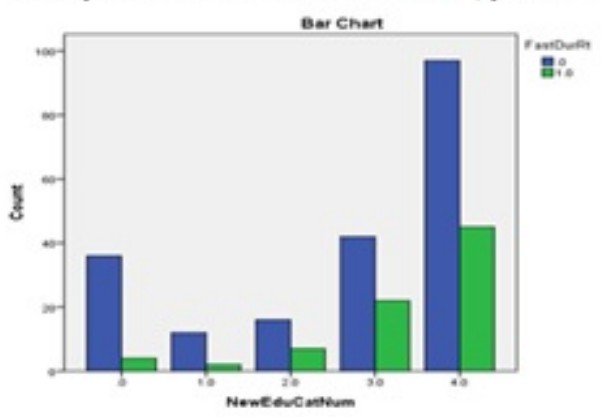

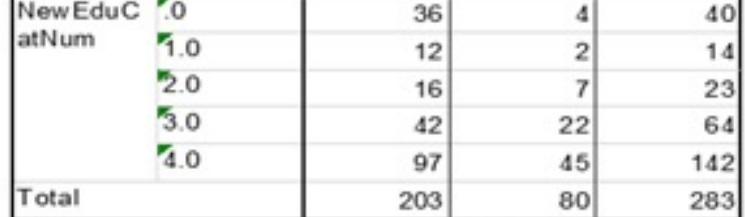

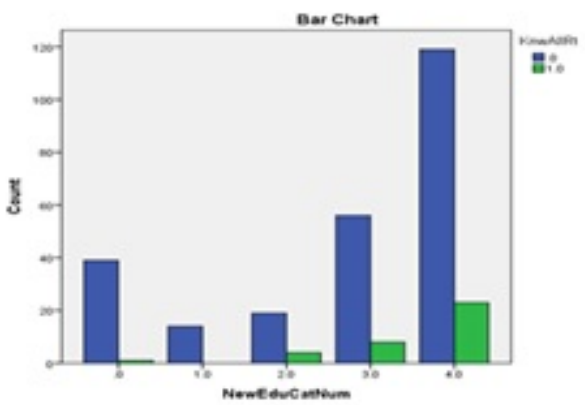

2C: Spearman Correlation +0.131 , p-value $=0.027^{*}$

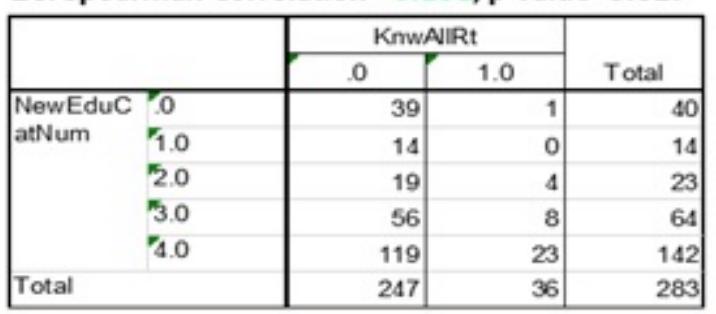

\section{B: Spearman Correlation -0.073 , p-value $=0.235$}
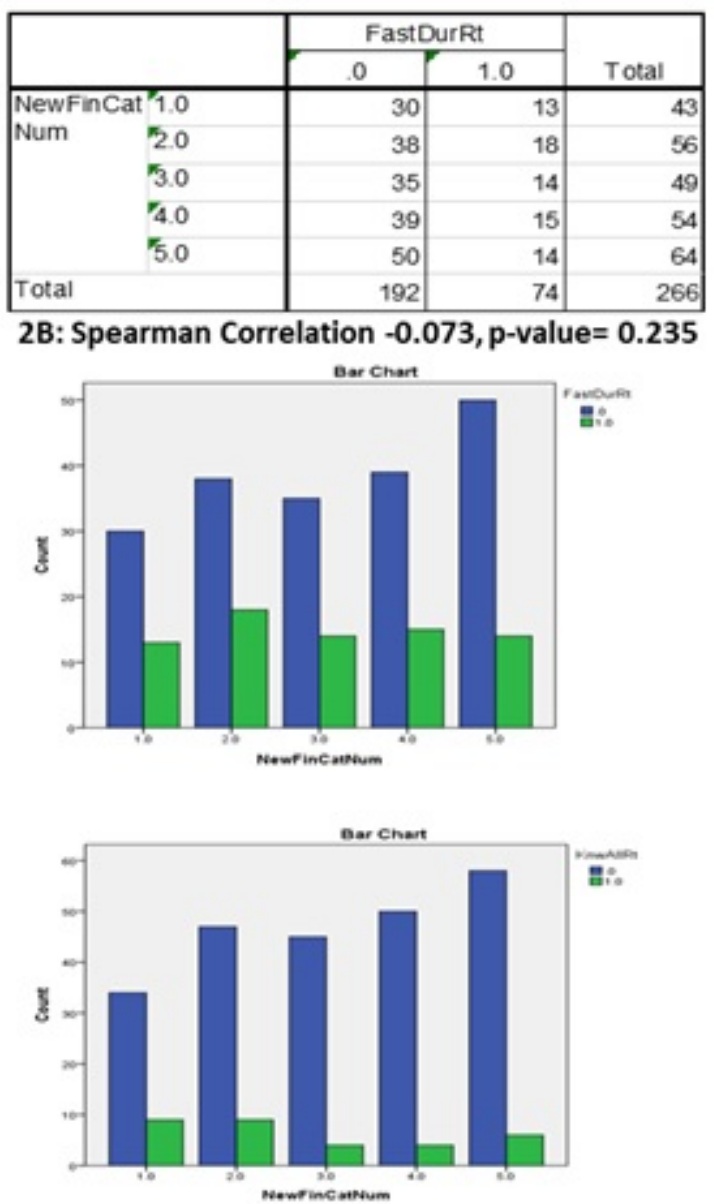

2D: Spearman Correlation -0.127 , p-value $=0.039^{*}$

\begin{tabular}{|c|c|c|c|}
\hline & \multicolumn{2}{|c|}{ KnwAIIRt } & \multirow[b]{2}{*}{ Total } \\
\hline & 0 & 1.0 & \\
\hline NewFinCat' 1.0 & 34 & 9 & 43 \\
\hline Num $\quad 2.0$ & 47 & 9 & 56 \\
\hline 3.0 & 45 & 4 & 49 \\
\hline 4.0 & 50 & 4 & 54 \\
\hline 5.0 & 58 & 6 & 64 \\
\hline Total & 234 & 32 & 266 \\
\hline
\end{tabular}




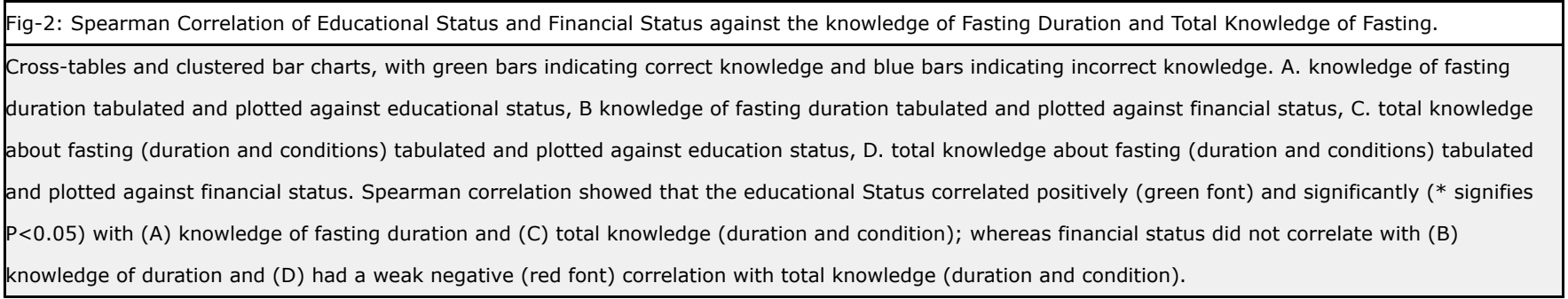

\section{Discussion}

Though the exact degree of reliance on medical decisions on laboratory investigations is difficult to delineate [17] its criticality is unquestionable. Poor investigation results lead to misdiagnosis and contribute to the burden of morbidity and mortality in many ways. Preanalytic variability, though relatively less standardized than the analytic phase, has several components that have been investigated for decades. However, patient preparation, though the most obvious and unavoidable, is still one of the most neglected components of the pre-analytic phase [18].

India is the "diabetes capital of the World" [19] with 45 million diabetics (15\% of the world's burden) living in this country. Rajasthan is the largest state in India that historically had a very low prevalence of diabetes ( $<5 \%$ in 1990). However, Rajasthan has shown an alarming jump in diabetes prevalence, increasing by $28-36 \%$ in the period $1990-2016$ [20]. Diagnosis and monitoring of diabetes become all the more important in this context, which critically depends upon the quality of glucose testing, which includes the quality and duration of the fasting.

In this study, it was found that a large majority $(71 \%)$ of our patients and a third of our educated controls did not remember receiving fasting instructions for glucose. Patients are on average less educated in formal school education (Table 1 ) but more affluent (Table 2) than the control group. So, as expected, patients had less knowledge or baseline understanding about duration and other conditions of fasting compared to controls and the majority came in improper fasting state quantitatively or qualitatively. Controls, though better by statistical significance, also were not properly prepared (Figure 1 and Table 6).

Education and instruction both make a significant impact and are associated with a better understanding of duration and other conditions.
However, the uniqueness of the present study is that the ability to see the significance levels of the impacts. It was found that instruction was way more significant (Table 9: $p$-value $=0.00000179$ ) than formal education (Table 10: $p$-value $=0.024$ ) in imparting the awareness about specific medical information regarding fasting.

In contrast to formal education, financial status (Fig. 2) did not have any positive association, but interestingly had a weak negative association with the total knowledge about fasting (Chi-Square borderline significant but Spearman correlation not significant). This finding suggests people who are financially more affluent are likely to be somewhat less complaint.

Instruction overall in the present study had only about $40 \%$ final effectiveness which suggests that there is a lot of scope of improvement in improving the content of the instruction and their modality of implementation. The high apparent awareness and compliance about alcohol and smoking found in the present study were likely false due to the shame of disclosure.

The lack of knowledge and poor compliance is partly amplified due to the diffuse responsibility of all stakeholders involved in the total testing process. The poor outcome testifies that, whether the information was provided or not, it was not retained well or adhered to. Some guidelines $[3,13]$ have recently been formulated to standardize the delivery of patient preparation information.

It is counterintuitive that under fasting may not always lead to higher estimates of glucose levels. Reactive hypoglycemia is seen in many conditions including early diabetes where a post-prandial sample may show glucose level relatively lower than fasting $[21,22]$. Thus the pre-analytic error introduced by the lack of instruction, understanding, or compliance in different aspects of fasting is complex and cannot be normalized post-analytically by some correction formula even if the current study retrospectively knew the exact error in the patient preparation. 
The primary way to prevent the error would be to improve the content, quality, intensity, and frequency of the information delivery to the patients and updating the training of their caregivers of all levels through as many means as possible.

While the physicians and policymakers involved in developing guidelines formulate the need for fasting and are responsible for systematically increasing public and professional awareness, it is the Laboratory professionals who implement the preanalytic phase and directly ensure the quality. A review of the guidelines of fasting in different countries [4] showed that the guidelines vary: e.g. for fasting glucose testing the USA, UK, and Italy ask for 8 hours of fasting, the only USA specifies that there should be no food or drink except water.

On the other hand, Australia and the Czech Republic recommend 8-10 hours of fasting, and Germany requires 12 hours of fasting overnight. Despite a few newer guidelines $[13,23]$, this field is still far from harmonization. Unless there is detailed research about the bottlenecks in the implementation, policymakers would not know the ground reality of how well the preanalytic guidelines are being implemented and where it needs to be improved.

Some of the limitations of the study include crosssectional design, inherent limitations of the survey as a tool (e.g. recall bias), and an unusual combination of the financially affluent but educationally diverse patient population in the catchment area of the hospital. These findings need to be replicated and corroborated and generalized by larger studies in a country like ours, which is heterogeneous in percolation of resources including information availability, health care facilities, and training of personnel as well as the level of education of the local population. The high apparent impact of instruction in patients was because the baseline level of knowledge was low. Also, because of the relatively affluent financial status of the average patients and the relatively small sample size, the current study did not have sufficient representation of the very poor or most underprivileged segment of the population in the Indian context.

There remains an unmet need to improve awareness on this topic at multiple levels, that needs to be done multi-modally including printed leaflets, posters, and audio-visual aids in addition to verbal reminders.
In the future, locally the current study planned to administer corrective actions both in the training of staff as well as the improvement in information content, administration, and reinforcement modalities, and check the effectiveness of these interventions and their evolution in time. At a larger level, it was planned to hold bigger systematic surveys and sensitize the policymakers Nationally and Internationally.

This study is going to contribute to the field of preanalytic clinical chemistry in India and Internationally in many ways. On one hand, it addresses a lack of harmonization in guideline content Nationally and Internationally, on the other hand, it also brings to attention the poor state of implementation of the guideline that perpetuates poor awareness which in turn amplifies the problem of quality delivery of medical services in multiple ways.

It should add to the literature used to formulate better harmonized preanalytic guidelines, and also it should lead to quality improvement interventions aimed at better percolation and implementation of the guideline at the grassroots levels.

Regarding patient preparation aspects of preanalytic clinical biochemistry, there are no published studies from India and very few studies exist Internationally $[24,10,18,11,25]$. One of the very few studies on a related topic from another Lower Middle Income Country (LMIC) [26] that could be located was Pant et al study from Nepal, [25] also points to a lack of harmonized definition and protocol for fasting.

A preanalytic survey done by one of the leading groups of the European Federation of Laboratory Medicine (EFLM) [10] found $52 \%$ of the patients were not informed about fasting and the rest $48 \%$ were also only partly informed.

The present study contrasts with this European study where baseline awareness for fasting was much higher, and rather some of the European subjects believed fasting was necessary for all tests. Another study from Australia [24] found that the female gender was associated with better patient understanding but the female gender did not show any difference in the present study.

A 2012 report by the European Commission [27] showed that the communication barrier between physicians and their patients was partly due to physicians' availability or time to explain. 
Laboratories also are supposed to have updated, clear, and understandable written instructions which unfortunately are rarely created or maintained. There should be clear policies for sample acceptance rules for fasting samples. "No-sample is better than a bad-sample" principle should be strictly enforced and re-training of the laboratory personnel should include an emphasis on this.

\section{What does the study add to the existing knowledge?}

The current study raises an alert that the present system of information delivery to patients is not able to achieve its intended goal. Revised recommendations should be more harmonized and include precise and practically executable requirements for patient preparation. For fasting blood glucose testing, the time of the day (7-9 AM), the exact range of fasting duration (8-12hours), and water consumption ad libitum, should be specified. At least verbal explanations to avoid religious snacks during fasting should be provided to help clarify the difference between medical fasting and religious fasting. Alcohol avoidance for $24 \mathrm{~h}$, abstinence from cigarette smoking and avoiding exercise in the morning, and strict restriction of calorific or stimulating beverages including tea, coffee, etc. should be promulgated.

\section{Author contributions}

Dr. Asmita Hazra: Study conceptualization and design, data collection

Dr. Saptarshi Mandal: Analysis and interpretation

Dr. Seema L. Jawalekar: Review and authorization

Dr. Jairam Rawtani: Review and authorization

Ms. Minal Marlecha: Data collection

\section{Reference}

01. Lippi G, Banfi G, Church S, Cornes M, De Carli G, Grankvist $K$, et al. Preanalytical quality improvement, In pursuit of harmony, on behalf of European Federation for Clinical Chemistry and Laboratory Medicine (EFLM) Working group for Preanalytical Phase (WG-PRE). Clin Chem Lab Med. 2015;53(3)357-370.

doi: $10.1515 / \mathrm{cclm}-2014-1051$ [Crossref]
02. Plebani M, Lippi G. Closing the brain-to-brain loop in laboratory testing. Clin Chem Lab Med. 2011;49(7)1131-1133.

doi: 10.1515/CCLM.2011.617 [Crossref]

03. Salinas M, Flores E, Puche CM, Lopez-Garrigos M, Leiva-Salinas C. Recommendations for the patient preparation for laboratory tests in primary care in Spain- A redconlab study. Clinica Chimica Acta. 2019;493; S705.

doi: $10.1016 /$ j.cca.2019.03.1560 [Crossref]

04. Simundic AM, Cornes M, Grankvist K, Lippi G, Nybo M. Standardization of collection requirements for fasting samples for the Working Group on Preanalytical Phase (WG-PA) of the European Federation of Clinical Chemistry and Laboratory Medicine (EFLM). Clinica Chimica Acta. 2014;432;33-37.

doi: 10.1016/j.cca.2013.11.008 [Crossref]

05. Lima-Oliveira G, Salvagno GL, Lippi G, Gelati M, Montagnana $M$, Danese $E$, et al. Influence of a regular, standardized meal on clinical chemistry analytes. Ann Lab Med. 2012;32(4)250-256.

doi: $10.3343 / \mathrm{alm} .2012 .32 .4 .250$ [Crossref]

06. Guidi GC, Simundic AM, Salvagno GL, Aquino JL, Lima-Oliveira $\mathrm{G}$. To avoid fasting time, more risk than benefits. Clin Chem Lab Med (CCLM). 2015;53(10)e261-e264.

doi: 10.1515/cclm-2014-1013 [Crossref]

07. Lippi G, Lima-Oliveira G, Salvagno GL, Montagnana M, Gelati M, Picheth $G$, et al. Influence of a light meal on routine haematological tests. Blood Transfus. 2010;8(2)94-99.

doi: $10.2450 / 2009.0142-09$ [Crossref]

08. Moebus S, Göres L, Lösch C, Jöckel KH. Impact of time since last caloric intake on blood glucose levels. Europe J Epidemiol. 2011;26(9)719-728. doi: $\quad 10.1007 / \mathrm{s} 10654-011-9608-z \quad$ [Crossref]

09. Nybo M, Grinsted P, Jørgensen PE. Blood Sampling- Is Fasting Properly Defined?. Clin Chem. 2005;51(8)1563-1564.

doi: 10.1373/clinchem.2005.051789 [Crossref] 
10. Kackov S, Simundic AM, Gatti-Drnic A. Are patients well informed about the fasting requirements for laboratory blood testing?. Biochemia Medica. 2013;23(3)326-331.

doi: $10.11613 / \mathrm{bm} .2013 .040$ [Crossref]

11. Nikolac N, Simundic AM, Kackov S, Serdar T, Dorotic A, Fumic K, et al. The quality and scope of information provided by medical laboratories to patients before laboratory testing- Survey of the Working Group for Patient Preparation of the Croatian Society of Medical Biochemistry and Laboratory Medicine. Clinica Chimica Acta. 2015;450;104-109.

doi: 10.1016/j.cca.2015.08.001 [Crossref]

12. POCT13- Glucose Monitoring Without Lab Support - CLSI. (nd). Clinical \& Laboratory Standards Institute. Retrieved Dec-25;2019.

Available from [Article] [Crossref]

13. Simundic AM, Bölenius K, Cadamuro J, Church $S$, Cornes MP, van Dongen-Lases EC, et al. Working Group for Preanalytical Phase (WGPRE), of the European Federation of Clinical Chemistry and Laboratory Medicine (EFLM) and Latin American Working Group for Preanalytical Phase (WG-PRE-LATAM) of the Latin America Confederation of Clinical Biochemistry (COLABIOCLI) Joint EFLM-COLABIOCLI Recommendation for venous blood sampling. Clin Chem Lab Med. 2018;56(12)2015-2038. doi: $10.1515 / \mathrm{cclm}-2018-0602$ [Crossref]

14. World Health Organization. Definition, diagnosis and classification of diabetes mellitus and its complications- Report of a WHO consultation, Part 1, Diagnosis and classification of diabetes mellitus. World Health Organization.

Available from [Article] [Crossref]

15. Citing SurveyMonkey. (nd) Retrieved Sept-25, 2019.

Available from [Article] [Crossref]

16. Dalvi TM, Khairnar MR, Kalghatgi SR. An Update of BG Prasad and Kuppuswamy Socio-Economic Status Classification Scale for Indian Population. Indian J Pediatr. 2020;87(7)567-568.

doi: $\quad 10.1007 / \mathrm{s} 12098-020-03200-7 \quad$ [Crossref]
17. Hallworth MJ. The ' $70 \%$ claim'- What is the evidence base?. Ann Clin Biochem. 2017;48(6)487-488.

doi: 10.1258/acb.2011.011177 [Crossref]

18. Salinas M, López-Garrigós M, Flores E, LeivaSalinas C. Current Practice and Regional Variability in Recommendations for Patient Preparation for Laboratory Testing in Primary Care. Lab Med. 2020;51(3)e32-e37. doi: 10.1093/labmed/Imz092 [Crossref]

19. Joshi SR, Parikh RM. India the diabetes capital of the world- Now heading towards hypertension. J Assoc Physic India. 2007; 55(Y)323.

[Crossref]

20. Tandon N, Anjana RM, Mohan V, Kaur T, Afshin $A$, Ong $K$, et al. The increasing burden of diabetes and variations among the states of India- the Global Burden of Disease Study 1990-2016. Lancet Global Health. 2018;6(12)e1352-e1362.

doi: $10.1016 / \mathrm{S} 2214-109 \times(18) 30387-5 \quad$ [Crossref]

21. Altuntaş Y. Postprandial Reactive Hypoglycemia. Şişli Etfal Hastanesi Tıp Bülteni. 2019;53(3)215220.

doi: $10.14744 /$ SEMB.2019.59455 [Crossref]

22. Sørensen M, Johansen OE. Idiopathic reactive hypoglycaemia-prevalence and effect of fibre on glucose excursions. Scandinavian J Clin Lab Investig. 2010;70(6)385-391.

doi: $10.3109 / 00365513.2010 .491869$ [Crossref]

23. Lippi G, Simundic AM. European Federation for Clinical Chemistry and Laboratory Medicine (EFLM) Working Group for Preanalytical Phase (WG-PRE), The EFLM strategy for harmonization of the preanalytical phase. Clin Chem Lab Med. 2018;56(10)1660-1666.

doi: $10.1515 / \mathrm{cclm}-2017-0277$ [Crossref]

24. Kljakovic M. Patients and tests- A study into patient understanding of blood tests ordered by their doctor. Australian Family Physician. $2012 ; 41(4) 241$.

[Crossref] 
25. Pant V, Gautam K, Pradhan S. Fasting Blood Glucose Test in Nepal-Time for a Harmonized Definition. J Nepal Health Res Council. 2019;17(2)267-268.

doi: $10.33314 /$ jnhrc.v0i0.1810 [Crossref]

26. New World Bank country classifications by income level- 2020-2021. (nd) Retrieved Jul-17, 2020.

Available from [Article] [Crossref]

27. Doe J. Eurobarometer Qualitative Study on patient involvement in healthcare [Text]. EUROPEAN INNOVATION PARTNERSHIP

European Commission. 2012; May 21.

Available from: [Article] [Crossref] 